\title{
ASSOCIATION BETWEEN PATTERNS IN AGRICULTURAL LANDSCAPES AND THE ABUNDANCE OF WHEAT APHIDS AND THEIR NATURAL ENEMIES
}

\author{
JUN-HE LIU ${ }^{1, *}$, MING-FU YU ${ }^{1}$, WEN-YI CUI ${ }^{1}$, LI SONG ${ }^{1}$, \\ ZI-HUA ZHAO ${ }^{2}$, and ABID ALI ${ }^{3}$

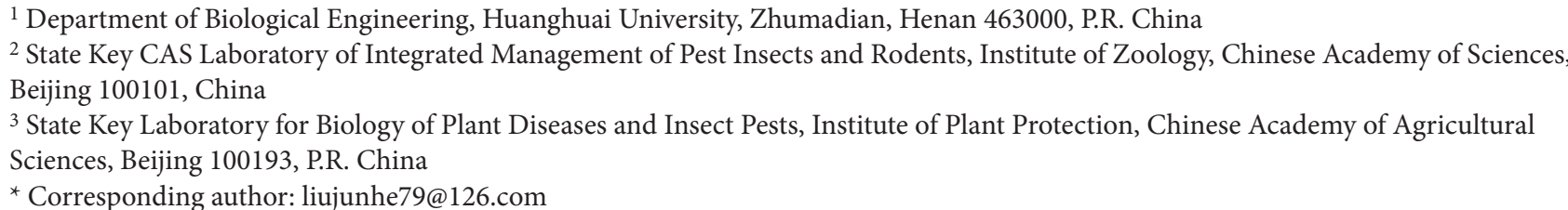

\section{ABSTRACT}

Effect of different landscape patterns on insect distribution and diversity was determined by studying wheat fields in complex and simple agricultural landscapes. We studied the influence of simple and complex agricultural landscapes on wheat aphids and their natural enemies in terms of the time of migration, abundance, population growth rate of the aphids and parasitoid abundance. The results indicate that the diversity of natural enemies is greater in the complex agricultural landscape and the effect of natural enemies on the abundance of wheat aphids was greater in the complex non-crop habitat. Wheat aphid hyperparasitoid populations differed in different agricultural landscapes with a greater number of parasites in complex agricultural landscapes. Resident times of predatory natural enemies differ in simple and complex agricultural landscapes. The number and types of predatory natural enemies are higher in complex than simple agricultural landscapes. Aphid population growth rates and the maximum population densities of wheat aphids differed significantly in simple and complex landscapes. Maximum population densities of different wheat aphids were very different in simple and complex landscape structures. The population growth rates and maximum population densities of the different predatory natural enemies and hyperparasitoids differed greatly.

Keywords: landscape pattern, natural enemy, population dynamics, wheat aphid

\section{Introduction}

Landscapes are composed of various types of habitats that could potentially determine the abundance of natural enemies (Bianchi et al. 2008). Natural enemies have the potential to control many insect pests and prevent outbreaks of insects in forests and agro-ecosystems (DeBach and Rosen 1991) and ultimately contribute to a reduction in the use of pesticides and their adverse effects on the environment (Naylor and Ehrlich 1997). In all agricultural landscapes, there are habitats that provide alternative food sources, hibernation sites and hosts or prey for natural enemies (Landis et al. 2000) and therefore the composition of landscapes has strong effect on the numerical responses of natural enemies (predators and parasitoids) (Elliott et al. 2001). The mechanism that results in species responding differently to landscapes composition is not the same for all species. In order to understand the ecology of landscape one needs to understand the spatial and temporal dynamics of organism (Wu and Hobbs 2002). Activity of insect pests can be affected by many aspects of landscape composition (Tscharntke and Brandl 2004; Hassan et al. 2012) and movement of species in landscapes is determined by habitat specificity and dispersal capacity (Roland and Taylor 1997; Wanger and Edwards 2001). Thus, the composition of landscapes is important in determining the movement of insect pests and natural enemies in a landscape.
The pattern of agricultural landscapes greatly influences insects and their relationship to predators and parasites. There is little research on the effect landscape patterns on insect communities and interspecies relationships (Vollhardt et al. 2008) but recently it has become an important topic for ecologists (Andrén 1994; Boutin et al. 2002; Haila 2002; Baguette et al. 2003; Dauber et al. 2003). This study included both heterogeneous and homogeneous landscapes with a gradient from simple agricultural landscapes in which most of the land was cultivated ( $89.3 \%$ arable) to complex agricultural landscapes in which a high percentage of the land was covered with non-crop habitats (39.6\% arable). In order to determine the relationships between wheat aphids and their natural enemies in simple and complex agricultural landscapes on the Yinchuang plain, we studied the distribution of the natural enemies of wheat aphids in different agricultural landscapes (Table 1). We propose to test the following hypotheses: 1) the complexity of the structure of a landscape and diversity of natural enemies of wheat aphids are positively correlated - the more complex the structure of the landscape, the greater the diversity of natural enemies. 2) structure of the landscape affects migration of winged wheat aphids and the numbers of parasites and predators recorded in different agricultural landscapes. This paper explores the effect of landscape on the numbers of natural enemies of wheat aphids. 
Table 1 Species composition of wheat aphids, parasitoids, hyperparasitoids and predators collected in spring wheat fields and reared in the laboratory.

\begin{tabular}{|c|c|c|c|}
\hline Pest group & Species & Complex agricultural landscape (CAL) & Simple agricultural landscape (SAL) \\
\hline \multirow{3}{*}{ Insects } & Macrosiphum avenae & $1757 \pm 235$ & $2376 \pm 428$ \\
\hline & Schizaphis graminum & $1318 \pm 152$ & $1790 \pm 192$ \\
\hline & Rhopalosiphum padii & $416 \pm 75$ & $598 \pm 83$ \\
\hline \multirow{8}{*}{ Parasitoids } & Aphidius avenae & $311 \pm 36$ & $447 \pm 51$ \\
\hline & A. gifuensis & $147 \pm 35$ & $214 \pm 44$ \\
\hline & A. sichuanensis & $15 \pm 4$ & $8 \pm 3$ \\
\hline & Trioxys asiaticus & $7 \pm 2$ & $8 \pm 3$ \\
\hline & Lysiphlebus confusus & $4 \pm 2$ & $9 \pm 3$ \\
\hline & Praon volucre & $6 \pm 3$ & $9 \pm 4$ \\
\hline & P. rhopalosiphum & $3 \pm 1$ & $6 \pm 2$ \\
\hline & Tetrastichus sp. & $2 \pm 1$ & $8 \pm 3$ \\
\hline \multirow{6}{*}{ Hyperparasitoids } & Asaphes vulgaris & $49 \pm 17$ & $35 \pm 13$ \\
\hline & Asaphes suspensus & $78 \pm 28$ & $68 \pm 23$ \\
\hline & Pachyneuron aphidis & $170 \pm 39$ & $119 \pm 34$ \\
\hline & Aphidencyrtus aphidivorus & $13 \pm 2$ & $7 \pm 3$ \\
\hline & Dendrocecrus carpenter & $9 \pm 3$ & $8 \pm 3$ \\
\hline & Alloxysta sp. 1 & $175 \pm 42$ & $131 \pm 36$ \\
\hline \multirow{30}{*}{ Predators } & Hippodamia tredecimpunctata & $8 \pm 3$ & $5 \pm 2$ \\
\hline & Hippodamia variegata & $6 \pm 2$ & $11 \pm 4$ \\
\hline & Coccinella septempunctata & $2 \pm 1$ & $5 \pm 2$ \\
\hline & Harmonia axyridis & $3 \pm 1$ & $4 \pm 2$ \\
\hline & Propylea japonica & $12 \pm 4$ & $7 \pm 3$ \\
\hline & Chrysopa sinica & $7 \pm 3$ & $8 \pm 3$ \\
\hline & C. formosa & $4 \pm 1$ & $6 \pm 2$ \\
\hline & Sympetrum croceolum & $3 \pm 1$ & $2 \pm 1$ \\
\hline & Chlaenius pallipes & $19 \pm 8$ & $59 \pm 15$ \\
\hline & Pterostichus gebleri & $4 \pm 1$ & $13 \pm 3$ \\
\hline & Cymindis binotata & $3 \pm 1$ & $21 \pm 6$ \\
\hline & Cymindis daimio & $4 \pm 1$ & $19 \pm 5$ \\
\hline & Calosma maderae & $5 \pm 2$ & $13 \pm 4$ \\
\hline & Scarites terricola & $6 \pm 1$ & $18 \pm 3$ \\
\hline & Harpalus crates & $9 \pm 2$ & $6 \pm 4$ \\
\hline & Harpalus salinus & $7 \pm 1$ & $4 \pm 2$ \\
\hline & Staphylinus maxillosus & $17 \pm 5$ & $21 \pm 7$ \\
\hline & Erigonidium graminicolum & $19 \pm 6$ & $27 \pm 8$ \\
\hline & Pardosa astrigera & $23 \pm 8$ & $39 \pm 12$ \\
\hline & Lycisa coelestris & $10 \pm 3$ & $13 \pm 4$ \\
\hline & Theridionocto macutatum & $5 \pm 2$ & $9 \pm 3$ \\
\hline & Misumenops tricuspidatus & $11 \pm 3$ & $19 \pm 5$ \\
\hline & Pardosa laura & $8 \pm 3$ & $5 \pm 2$ \\
\hline & Tetragnatha shikokiana & $9 \pm 3$ & $7 \pm 2$ \\
\hline & Xysticus ephippiatus & $18 \pm 5$ & $12 \pm 4$ \\
\hline & Erigone prominens & $14 \pm 5$ & $11 \pm 2$ \\
\hline & Agelena opulenta & $8 \pm 2$ & $3 \pm 1$ \\
\hline & Scaeva selenitica & $3 \pm 1$ & $5 \pm 2$ \\
\hline & Syrphus corollae & $9 \pm 3$ & $21 \pm 4$ \\
\hline & Syrphus nitens & $8 \pm 3$ & $19 \pm 5$ \\
\hline
\end{tabular}

European Journal of Environmental Sciences, Vol. 3, No. 2 


\section{Materials and Methods}

\section{Study region and experimental design}

The study was conducted in Yinchuan $\left(38^{\circ} 26^{\prime} 05 \mathrm{~N}\right.$, $106^{\circ} 22^{\prime} 04 \mathrm{E}$ ) in Ningxia Province, PR China. The areas studied were assigned to the following categories of landscape: (1) complex agriculture (CAL hereafter) or highly heterogeneous agricultural areas, (2) simple agriculture (SAL hereafter) or homogenous agricultural areas (Zhao Zihua 2010). There were three study areas: I - Xixia army horse ranch in Yinchuan, Ningxia (complex landscape); II - Zhangzheng Bridge in Xingqing district (complex landscape); III - Zhangzheng town in Xingqing district (simple landscape). In all the regions studied no pesticides were applied and they were managed according to the recommended production technology for that area and crop. They were studied from May to July in 2009, 2010 and 2011. Wheat aphids generally tend to stay and increase in numbers in a field before flying away. A five-point (East, South, West, North and Center) sampling grid was established, depending on the local characteristics. A total of 70 wheat fields of different sizes in different landscapes were studied.

\section{Wheat aphid populations recorded in different periods}

Three important factors in the population dynamics of aphids were recorded on different dates throughout the sampling period in 2009, 2010 and 2011: (1) appearance in the fields (10 April - 15 May), (2) period of population growth (16-30 May), and (3) peak numbers (30 May -
20 June). The aphids and natural enemies were counted at intervals of 10 days from 15th April to 20th June.

\section{Monitoring of arthropods / Insect Sampling}

Method used to survey wheat aphids: At each point on the grid 100 representative wheat plants were randomly selected. Each of these plants was examined over a period of 15-20 min and any $M$. avenae, S. graminum or $R$. padi and wingless aphids present on the plants were recorded thereby generating five sets of data for the grid (Table 2).

Method used to survey parasitoids: Using the grid described above, 100 wheat plants were randomly selected and visually examined for 15-20 min. The number of mummified aphids, S. graminum and R. padi and wingless aphids were counted. Mummified aphids were taken to the laboratory and placed in a Petri dish labeled with the date of collection and a sample code number and kept under the following conditions $\left(16: 8 \mathrm{~L}: \mathrm{D}, 20 \pm 1{ }^{\circ} \mathrm{C}, \mathrm{RH}=65 \pm 3 \%\right)$ in an incubator. Over a period of more than 40 days we recorded whether parasitoids had emerged from mummies every day at 5:00 PM. These parasitoids and the aphid mummies were stored in $90 \%$ alcohol prior to identification.

Net method: Predators were surveyed using the same checkerboard 5 point random sampling grid described above. Each position on the grid was swept 10 times. Ten adult insects from each sweep of the net were collected and together with debris placed in a poison bottle, with a total of five bottles collected at each position. All adult

Table 2 Sampling parameters used in agricultural landscape patterns.

\begin{tabular}{|c|c|c|c|}
\hline Sample parameters & Order & Family & Species \\
\hline \multirow{3}{*}{ Aphids } & Homoptera & Aphidinea & Macrosiphum avenae (F.) \\
\hline & Homoptera & Aphidinea & Schizaphis graminum (Rond) \\
\hline & Homoptera & Aphidinea & Rhopalosiphum padi (L.) \\
\hline \multirow{5}{*}{ Primary Parasitoids } & Hymenoptera & Aphididae & Aphidius avenae \\
\hline & Hymenoptera & Aphididae & A. sichuanensis \\
\hline & Hymenoptera & Braconidae & A. gifuensis \\
\hline & Hymenoptera & Aphididae & Lysiphlebus confusus \\
\hline & Hymenoptera & Aphididae & Praon volucre \\
\hline \multirow{5}{*}{ Secondary Parasitoids } & Hymenoptera & Charipidae & Alloxysta sp. \\
\hline & Hymenoptera & Pteromalidae & Pachyneuron aphidis (Bouche) \\
\hline & Hymenoptera & Pteromalidae & Asaphes suspensus Nees \\
\hline & Hymenoptera & Pteromalidae & Asaphes vulgaris Walker \\
\hline & Hymenoptera & Megaspilidae & Dendrocerus carpenteri (Curtis) \\
\hline \multirow{7}{*}{ Predators } & Coleoptera & Coccinellidae & Hippodamia tredecimpunctata (Say) \\
\hline & Coleoptera & Coccinellidae & Hippodamia variegata (Goeze) \\
\hline & Diptera & Syrphidae & Metasyrphus corollae Matsumura \\
\hline & Coleoptera & Carabidae & Chlaenius pallipes Gebler \\
\hline & Neuroptera & Chrysopidae & Chrysopa intima \\
\hline & Araneae & Lycosidae & Pardosa astrigera Koch \\
\hline & Hemiptera & Miridae & Deraeocoris punctulatus (Fallen) \\
\hline
\end{tabular}


specimens brought back to the laboratory were identified to species. Any nymphs collected were taken back to the laboratory and reared to the adult stage and identified, and the numbers of each of the species noted.

Trap method: Beetles and spiders in the wheat fields were captured on the ground and in the soil. Disposable plastic cups (height $9 \mathrm{~cm}$ diameter $7.5 \mathrm{~cm}$ ) were used as traps. Five sampling points were established in each plot and 5 cups placed at each sampling point so that in each plot there were 25 cups. The attractant placed in the cups was a $2: 1: 1: 20$ mixture of vinegar, sugar, methanol and water by weight. Each cup contained $40 \sim 60 \mathrm{ml}$ of this mixture. The cups were inspected every six days when all the arthropods were removed and taken back to the laboratory for identification and the attractant in the cup was replaced and the trap reset.

The large soil animals were hand-sorted and placed in $75 \%$ alcohol. Small soil animals were extracted from the soil using a Tullgren funnel ( $2 \mathrm{~mm}$ standard sieve) and the specimens collected and sorted using a zoom microscope and preserved in $75 \%$ alcohol prior to identification.

\section{Statistical analysis}

The numbers of cereal aphids and their natural enemies were subjected to one way analysis of variance (ANOVA) using statistical software (SAS institute Inc., 2006). Means of numbers of cereal aphids and their natural enemies were compared using LSD and a 5\% level of significance.

\section{Results}

\section{The effect of agricultural landscape on the time of the colonization of wheat field by aphids and their natural enemies}

Parasitoids: The parasitoids were first recorded in the different agricultural landscape at about the same time.
The first record of $A$. avenae in fields in the complex agricultural landscape was 26 April and 10 days later in the simple agricultural landscape (Table 3). The other parasitic wasps also occurred later in the simple landscape except for L. confusus, which occurred there earlier. Significantly more parasitic wasps were recorded in the complex agricultural landscape and only L. confusus was more abundant in the simple landscape. The total number of parasitoids in the complex landscape was significantly greater than in the simple landscape (Table 3).

Hyperparasitoids: All species of hyperparasitoids were recorded a few days earlier in the complex landscape (Table 4). The number of individuals of each hyperparasitoid recorded varied. The numbers of $P$. aphidis, A. suspensus and A. vulgaris were significantly greater in the complex landscape. But the number of $D$. carpenteri was significantly higher in the simple landscape and that of Alloxysta sp was not significantly different in the two landscapes (Table 4). The total number of hyperparasitoids was significantly higher in the complex landscape.

Predators: The first predators were recorded at different times in the two agricultural landscapes. The predators were all first recorded during the period when the aphids first arrived in the fields (10 April to 15 May). Predators were first recorded later in the simple landscape, except for H. tredecimpunctata (Table 5). C. pallipes, $P$. astrigera and aphids were all recorded on the first day the fields were sampled in both the complex and simple landscapes and it is possible that they overwintered in the wheat fields.

The numbers of all the species of predators were significantly greater in the complex landscape (Table 5). The total number of species of predators was significantly greater in the complex landscape.

Table 3 Effects of different agricultural landscapes on the time of the appearance and numbers of parasitoids in wheat fields. The aphids were first recorded 10 April - 15 May.

\begin{tabular}{|l|l|c|c|}
\hline \multicolumn{2}{|c|}{ Parasitoid species } & Complex agricultural landscape (CAL) \pm SE & Simple agricultural landscape(SAL) \pm SE \\
\hline \multirow{3}{*}{ Aphidius avenae } & Time of appearance & 26 April & 16 April \\
\cline { 2 - 4 } & Numbers & $0.46 \pm 0.28 \mathrm{a}$ & $0.32 \pm 0.22 \mathrm{~b}$ \\
\hline \multirow{3}{*}{ A. gifuensis } & Time of appearance & 10 May & 5 May \\
\cline { 2 - 4 } & Numbers & $0.56 \pm 0.27 \mathrm{a}$ & $0.36 \pm 0.18 \mathrm{~b}$ \\
\hline \multirow{3}{*}{ A. sichuanensis } & Time of appearance & 13 May & $0.16 \pm 0.17 \mathrm{~b}$ \\
\cline { 2 - 4 } & Numbers & $0.23 \pm 0.11 \mathrm{a}$ & 8 May \\
\hline \multirow{3}{*}{ Lysiphlebus confusus } & Time of appearance & 30 April & $0.11 \pm 0.08 \mathrm{~b}$ \\
\cline { 2 - 4 } & Numbers & $0.08 \pm 0.05 \mathrm{a}$ & 8 May \\
\hline \multirow{2}{*}{ Praon volucre } & Time of appearance & 13 May & $0.12 \pm 0.14 \mathrm{~b}$ \\
\cline { 2 - 4 } & Numbers & $0.14 \pm 0.07 \mathrm{a}$ & 16 April \\
\hline \multirow{2}{*}{ Total parasitoids } & Time of appearance & $26 \mathrm{April}$ & $1.07 \pm 0.42 \mathrm{~b}$ \\
\cline { 2 - 4 } & Numbers & $1.47 \pm 0.53 \mathrm{a}$ & \\
\hline
\end{tabular}


Table 4 Effects of different agricultural landscapes on the time of the appearance and numbers of hyperparasitoids in wheat fields. Hyperparasitoids were first recorded 10 April - 15 May.

\begin{tabular}{|l|l|c|c|}
\hline \multicolumn{2}{|c|}{ Hyperparasitoid species } & Complex agricultural landscape (CAL) \pm SE & Simple agricultural landscape(SAL) \pm SE \\
\hline \multirow{3}{*}{ Alloxysta sp. } & Time of appearance & 8 May & 15 May \\
\cline { 2 - 4 } & Numbers & $0.59 \pm 0.24 \mathrm{a}$ & $0.33 \pm 0.18 \mathrm{a}$ \\
\hline \multirow{3}{*}{ Pachyneuron aphidis } & Time of appearance & 2 May & 10 May \\
\cline { 2 - 4 } & Numbers & $0.88 \pm 0.25 \mathrm{a}$ & $0.46 \pm 0.16 \mathrm{~b}$ \\
\hline \multirow{2}{*}{ Asaphes suspensus } & Time of appearance & 2 May & 10 May \\
\cline { 2 - 4 } & Numbers & $0.51 \pm 0.13 \mathrm{a}$ & $0.29 \pm 0.07 \mathrm{~b}$ \\
\hline \multirow{3}{*}{ Asaphes vulgaris } & Time of appearance & 10 May & 15 May \\
\cline { 2 - 4 } & Numbers & $0.26 \pm 0.11 \mathrm{a}$ & $0.19 \pm 0.07 \mathrm{~b}$ \\
\hline \multirow{2}{*}{$\begin{array}{l}\text { Dendrocerus } \\
\text { carpenteri }\end{array}$} & Time of appearance & 15 May & 20 May \\
\cline { 2 - 4 } & Numbers & $0.11 \pm 0.06 \mathrm{a}$ & $0.28 \pm 0.10 \mathrm{~b}$ \\
\hline \multirow{2}{*}{$\begin{array}{l}\text { Total } \\
\text { hyperparasitoids }\end{array}$} & Time of appearance & 2 May & 10 May \\
\cline { 2 - 4 } & Numbers & $2.35 \pm 0.41 \mathrm{a}$ & $1.55 \pm 0.32 \mathrm{~b}$ \\
\hline
\end{tabular}

\section{Effects of the structure of the landscape on the population growth rate and maximum population density of wheat aphids and their natural enemies}

Aphids: The population growth rate and maximum population density of $M$. avenae was 6 and 2 times greater, respectively, in the simple than in the complex landscape (Table 6). For S. graminum the population growth rates were significantly greater in the complex landscape, but the maximum population density they achieved was significantly greater in the simple landscape. $R$. padi achieved significantly higher population growth rates and maximum population densities in the complex landscape. The averages of the population growth rates and maximum population densities of all the species of aphids were significantly higher in the complex landscape.

Parasitoids: There were no significant differences in population growth rates or maximum population densities of parasitoids in the complex and simple landscapes (Table 7) except for A. avenae, which achieved significantly higher population densities $(F=36.26, \mathrm{df}=14$, $p=0.0001)$ in the complex landscape and $P$. volucre with significantly higher population growth rates $(F=28.86$, the $\mathrm{df}=14, p=0.0001)$ in the simple landscape. Total population growth rates were not significantly different in the two landscapes but the maximum population density was significantly greater $(F=18.62, \mathrm{df}=14$, $p=0.026)$ in the complex landscape.

Table 5 Effects of different agricultural landscapes on the time of the appearance time and numbers of predators in wheat fields. Aphids first recorded, 10 April - 15 May.

\begin{tabular}{|l|l|l|l|}
\hline \multicolumn{2}{|c|}{ Predator species } & Complex agricultural landscape (CAL) \pm SE & Simple agricultural landscape(SAL) \pm SE \\
\hline \multirow{2}{*}{$\begin{array}{l}\text { Hippodamia } \\
\text { tredecimpunctata }\end{array}$} & Time of appearance & 26 April & 16 April \\
\cline { 2 - 4 } Hippodamia variegata & Numbers & $0.93 \pm 0.41 \mathrm{a}$ & $0.41 \pm 0.26 \mathrm{~b}$ \\
\hline \multirow{3}{*}{ Metasyrphus corollae } & Time of appearance & 2 May & 10 May \\
\cline { 2 - 4 } & Numbers & $0.41 \pm 0.19 \mathrm{a}$ & $0.33 \pm 0.19 \mathrm{a}$ \\
\hline \multirow{3}{*}{ Chlaenius pallipes } & Time of appearance & 2 May & 10 May \\
\cline { 2 - 4 } & Numbers & $0.79 \pm 0.26 \mathrm{a}$ & $0.31 \pm 0.14 \mathrm{~b}$ \\
\hline \multirow{3}{*}{ Chrysopa intima } & Time of appearance & $10 \mathrm{April}$ & 10 April \\
\cline { 2 - 4 } & Numbers & $5.62 \pm 3.19 \mathrm{a}$ & $1.62 \pm 1.27 \mathrm{~b}$ \\
\hline \multirow{2}{*}{ Pardosa astrigera } & Time of appearance & $30 \mathrm{April}$ & $8 \mathrm{May}$ \\
\cline { 2 - 4 } & Numbers & $0.52 \pm 0.37 \mathrm{a}$ & $0.23 \pm 0.12 \mathrm{a}$ \\
\hline \multirow{2}{*}{ Deraeocoris punctulatus } & Time of appearance & $10 \mathrm{April}$ & 10 April \\
\cline { 2 - 4 } & Numbers & $3.18 \pm 0.93 \mathrm{a}$ & $1.86 \pm 0.53 \mathrm{~b}$ \\
\hline \multirow{2}{*}{ Total predators } & Time of appearance & $26 \mathrm{April}$ & $5 \mathrm{May}$ \\
\cline { 2 - 4 } & Numbers & $1.09 \pm 0.61 \mathrm{a}$ & $0.88 \pm 0.37 \mathrm{a}$ \\
\cline { 2 - 4 } & Time of appearance & 10 May & 10 May \\
\cline { 2 - 4 } & Numbers & $11.54 \pm 3.62 \mathrm{a}$ & $5.64 \pm 1.21 \mathrm{~b}$ \\
\hline
\end{tabular}


Table 6 Effects of the structure of the landscape on the population growth rate and maximum population density of wheat aphids.

\begin{tabular}{|l|l|c|c|}
\hline \multicolumn{2}{|c|}{ Aphid species } & Complex agricultural landscape (CAL) \pm SE & Simple agricultural landscape(SAL) \pm SE \\
\hline \multirow{2}{*}{ Macrosiphum avenae } & Growth rate & $29.13 \pm 4.76 \mathrm{~b}$ & $4.845 \pm 0.95 \mathrm{a}$ \\
\cline { 2 - 4 } & Max population density & $286.42 \pm 49.32 \mathrm{~b}$ & $144.82 \pm 26.33 \mathrm{a}$ \\
\hline \multirow{2}{*}{ Schizaphis graminum } & Growth rate & $53.25 \pm 15.32 \mathrm{~b}$ & $30.21 \pm 16.42 \mathrm{a}$ \\
\cline { 2 - 4 } & Max population density & $319.32 \pm 57.32 \mathrm{a}$ & $396.54 \pm 36.91 \mathrm{~b}$ \\
\hline \multirow{2}{*}{ Rhopalosiphum padi } & Growth rate & $43.43 \pm 25.32 \mathrm{a}$ & $25.62 \pm 9.35 \mathrm{a}$ \\
\cline { 2 - 4 } & Max population density & $252.83 \pm 45.32 \mathrm{~b}$ & $136.56 \pm 28.32 \mathrm{a}$ \\
\hline \multirow{2}{*}{ Total wheat aphids } & Growth rate & $39.43 \pm 11.84 \mathrm{~b}$ & $13.73 \pm 7.49 \mathrm{a}$ \\
\cline { 2 - 4 } & Max population density & $821.65 \pm 66.56 \mathrm{~b}$ & $677.81 \pm 32.98 \mathrm{a}$ \\
\hline
\end{tabular}

Table 7 Effects of different agricultural landscapes on the population growth rate and maximum population density of parasitoids in wheat fields.

\begin{tabular}{|l|l|c|c|}
\hline \multicolumn{2}{|c|}{ Parasitoid species } & Complex agricultural landscape (CAL) \pm SE & Simple agricultural landscape(SAL) \pm SE \\
\hline \multirow{3}{*}{ Aphidius avenae } & Growth rate & $18.63 \pm 3.62$ & $21.65 \pm 6.93$ \\
\cline { 2 - 4 } & Max population density & $139.62 \pm 32.63 \mathrm{a}$ & $96.83 \pm 21.83 \mathrm{~b}$ \\
\hline \multirow{3}{*}{ A. gifuensis } & Growth rate & $11.26 \pm 2.93$ & $13.52 \pm 4.83$ \\
\cline { 2 - 4 } & Max population density & $62.53 \pm 18.63$ & $46.83 \pm 15.81$ \\
\hline \multirow{3}{*}{ A. sichuanensis } & Growth rate & $9.63 \pm 2.83$ & $7.82 \pm 1.99$ \\
\cline { 2 - 4 } & Max population density & $1.26 \pm 0.28$ & $1.13 \pm 0.19$ \\
\hline \multirow{3}{*}{ Lysiphlebus confusus } & Growth rate & $7.26 \pm 2.92$ & $9.36 \pm 3.62$ \\
\cline { 2 - 4 } & Max population density & $0.92 \pm 0.19$ & $0.83 \pm 0.21$ \\
\hline \multirow{3}{*}{ Praon volucre } & Growth rate & $3.25 \pm 1.16 \mathrm{~b}$ & $5.36 \pm 1.83 \mathrm{a}$ \\
\cline { 2 - 4 } & Max population density & $1.08 \pm 0.31$ & $1.24 \pm 0.418$ \\
\hline \multirow{2}{*}{ Total parasitoids } & Growth rate & $10.01 \pm 3.63$ & $11.71 \pm 4.82$ \\
\cline { 2 - 4 } & Max population density & $205.41 \pm 43.26 \mathrm{a}$ & $146.86 \pm 31.63 \mathrm{~b}$ \\
\hline
\end{tabular}

Table 8 Effects of different agricultural landscapes on the population growth rate and maximum population density of hyperparasitoids in wheat fields.

\begin{tabular}{|l|l|c|c|}
\hline \multicolumn{2}{|c|}{ Hyperparasitoid species } & Complex agricultural landscape (CAL) \pm SE & Simple agricultural landscape(SAL) \pm SE \\
\hline \multirow{2}{*}{ Alloxysta sp. } & Growth rate & $21.38 \pm 6.83$ & $16.89 \pm 5.88$ \\
\cline { 2 - 4 } & Max population density & $42.29 \pm 15.62$ & $35.09 \pm 11.24$ \\
\hline \multirow{2}{*}{ Pachyneuron aphidis } & Growth rate & $13.62 \pm 4.26$ & $9.39 \pm 3.19$ \\
\cline { 2 - 4 } & Max population density & $39.95 \pm 14.59$ & $35.26 \pm 16.93$ \\
\hline \multirow{2}{*}{ Asaphes suspensus } & Growth rate & $11.22 \pm 3.13$ & $8.92 \pm 2.12$ \\
\cline { 2 - 4 } & Max population density & $26.38 \pm 8.69$ & $22.83 \pm 7.93$ \\
\hline \multirow{3}{*}{ Asaphes vulgaris } & Growth rate & $7.26 \pm 2.92$ & $9.36 \pm 3.62$ \\
\cline { 2 - 4 } & Max population density & $18.62 \pm 5.93$ & $26.83 \pm 7.63$ \\
\hline \multirow{2}{*}{$\begin{array}{l}\text { Dendrocerus } \\
\text { carpenteri }\end{array}$} & Growth rate & $9.63 \pm 3.61$ & $8.92 \pm 4.62$ \\
\cline { 2 - 4 } & Max population density & $4.68 \pm 1.36$ & $3.26 \pm 1.06$ \\
\hline \multirow{2}{*}{ Total hyperparasitoids } & Growth rate & $12.62 \pm 4.12$ & $10.68 \pm 3.99$ \\
\cline { 2 - 4 } & Max population density & $132.92 \pm 49.83$ & $122.27 \pm 38.89$ \\
\hline
\end{tabular}

Hyperparasitoids: There were no significant differences in population growth rates or maximum population densities of hyperparasitoids in the complex and simple landscapes (Table 8). In total there were five main species of hyper-parasitoids the population growth rates and the maximum population densities of which were greater in the complex than the simple agricultural landscape. They were: Alloxysta sp. $(21.38 \pm 6.83$ vs. $16.89 \pm 5.88$, $42.29 \pm 15.62$ vs. $35.09 \pm 11.24)$, Pachyneuron aphidis
(13.62 \pm 4.26 vs. $9.39 \pm 3.19,39.95 \pm 14.59$ vs. $35.26 \pm$ 16.93), Asaphes suspensus (11.22 \pm 3.13 vs. $8.92 \pm 2.12$, $26.38 \pm 8.69$ vs. $22.83 \pm 7.93)$, Dendrocerus carpenteri ( $9.63 \pm 3.61$ vs. $8.92 \pm 4.62,4.68 \pm 1.36$ vs. $3.26 \pm 1.06)$, but the differences are not significant. Only the population growth rates (7.26 \pm 2.92 vs. $9.36 \pm 3.62)$ and max population density (18.62 \pm 5.93 vs. $26.83 \pm 7.63)$ of Pachyneuron were greater in the complex landscape, but the differences $(F=5.19, \mathrm{df}=14, p=0.062$, table 9$)$ are not significant. 
Table 9 Effects of different agricultural landscapes on the population growth rate and maximum population density of predators in wheat fields.

\begin{tabular}{|l|l|c|c|}
\hline \multicolumn{2}{|c|}{ Predator species } & Complex agricultural landscape (CAL) \pm SE & Simple agricultural landscape(SAL) \pm SE \\
\hline \multirow{2}{*}{$\begin{array}{l}\text { Hippodamia } \\
\text { tredecimpunctata }\end{array}$} & Growth rate & $7.26 \pm 2.39$ & $5.36 \pm 2.03$ \\
\cline { 2 - 4 } $\begin{array}{l}\text { Hippodamia varie- } \\
\text { gata }\end{array}$ & Max population density & $10.67 \pm 3.60$ & $6.91 \pm 2.38$ \\
\hline \multirow{2}{*}{ Metasyrphus corollae } & Growth rate & $6.45 \pm 2.31$ & $5.26 \pm 1.96$ \\
\cline { 2 - 4 } & Max population density & $13.83 \pm 3.66$ & $11.22 \pm 4.06$ \\
\cline { 2 - 4 } & Growth rate & $8.63 \pm 4.26 \mathrm{a}$ & $3.19 \pm 1.01 \mathrm{~b}$ \\
\hline \multirow{3}{*}{ Chlaenius pallipes } & Growth rate & $1.31 \pm 0.34 \mathrm{a}$ & $0.68 \pm 0.14 \mathrm{~b}$ \\
\cline { 2 - 4 } & Max population density & $0.87 \pm 0.22 \mathrm{a}$ & $0.43 \pm 0.11 \mathrm{~b}$ \\
\hline \multirow{3}{*}{ Chrysopa intima } & Growth rate & $4.38 \pm 1.09 \mathrm{a}$ & $1.01 \pm 0.16 \mathrm{~b}$ \\
\cline { 2 - 4 } & Max population density & $14.09 \pm 5.21 \mathrm{a}$ & $8.67 \pm 2.34 \mathrm{~b}$ \\
\hline \multirow{2}{*}{ Pardosa astrigera } & Growth rate & $7.63 \pm 2.26 \mathrm{a}$ & $5.29 \pm 3.01 \mathrm{~b}$ \\
\cline { 2 - 4 } & Max population density & $1.26 \pm 0.41$ & $1.52 \pm 0.71$ \\
\hline \multirow{2}{*}{$\begin{array}{l}\text { Deraeocoris } \\
\text { punctulatus }\end{array}$} & Growth rate & $5.66 \pm 2.36$ & $6.29 \pm 3.21$ \\
\cline { 2 - 4 } Total predators & Max population density & $3.62 \pm 1.21$ & $2.38 \pm 0.92$ \\
\hline \multirow{2}{*}{ Growth rate } & $2.69 \pm 0.88$ & $2.37 \pm 0.79$ \\
\cline { 2 - 4 } & Max population density & $5.88 \pm 1.88 \mathrm{a}$ & $3.83 \pm 1.36 \mathrm{~b}$ \\
\hline
\end{tabular}

Predators: The population growth rates and maximum population densities of the 7 species of predators differed in the complex and simple landscapes (Table 9). In the cases of $H$. tredecimpunctata, $H$. variegata, $P$. astrigera and D. punctulatus, however, the differences were not significant, but for the other three species both the population growth rates and maximum population densities differed significantly. For M. corollae, C. pallipes and $C$. intima the population growth rates $(F=19.69$, df $=14, p=0.029 ; F=16.82, \mathrm{df}=14, p=0.034 ; F=13.62$, $\mathrm{df}=14, p=0.038)$ and population densities $(F=23.92 \mathrm{df}$ $=14, p=0.021 ; F=39.95, \mathrm{df}=14, p=0.001 ; F=12.66$, $\mathrm{df}=14, p=0.041)$ were both significantly greater in the complex landscape.. Both the total population growth rate and the maximum population density of predators was significantly higher in the complex than in the simple landscape $(F=22.69, \mathrm{df}=14, p=0.23 ; F=28.91$, $\mathrm{df}=14, p=0.018$ ).

\section{Discussion}

\section{Population dynamics of wheat aphids in different landscapes}

There is no need to control wheat aphids in northern China, because the wheat aphid populations that occur there are relatively low. The number of alatae recorded in the two landscapes differed. Although the numbers of alatae recorded in the complex landscape was significantly lower than the simple landscape, the population growth rate of the aphids was considerably different possibly because of the high degree of fragmentation of the complex landscape, which makes it more difficult for natural enemies to find prey. But wheat aphids need to be controlled in the south of China.
Wheat aphid abundance was not affected by the structure of the landscape, which is consistent with the findings of Costamagna et al.s (2004) study on Pseudaletia unipuncta. Here we think it is likely that wheat aphid abundance is not affected by the complexity of the structure of the landscape but by the degree of fragmentation of host plant habitats in the landscape.

\section{Percentage parasitism}

The difference in percentage parasitism recorded in complex and simple landscapes was very slight. This may be attributable to the following: (1) landscape structure affects the richness and diversity of parasitic wasps but not in the area studied. (2) non-crop habitats limits the richness and transfer of parasitic wasps. (3) difference in the population dynamics of the parasitic wasps and aphids. The little difference in the percentage parasitism in the two landscapes may because the population density of the host in the two landscapes is as Costamagna et al. (2004) and Zhao et al. (2012) have shown very similar and host density is usually the main factor determining percentage parasitism. The richness and diversity of parasitic wasps increased with host density with a higher diversity in the simple landscape, which is what theory predicts. A high percentage of grassland in a landscape is associated with an increased number of predatory natural enemies and increase in the control of the wheat aphid population. An increase in the complexity of the structure of the landscape is also associated with an increase in the diversity of predatory natural enemies. Therefore, the design of agricultural landscapes should take into consideration the need to maintain species diversity. At the landscape scale, increasing the proportion of grassland in an agricultural landscape can also strengthen the role of the natural enemies 
in biological control by maintaining a higher diversity of natural enemies. Designing landscapes that facilitate biological control by increasing the efficiency of natural enemies and reducing the colonization of crops by pests is ultimately a reasonable use of resources. Mosaic landscapes should include grassland, woodland, wetland, buildings, roads etc. We should make full use of these resources to enhance biological control and the value of ecosystem services. Landscape planning may be the most effective means of increasing the numbers of natural enemies, especially in agricultural landscapes.

\section{The diversity of parasitoids and variation in percentage parasitism}

The diversity parasitoids and percentage parasitism of aphids in a complex landscape were lower than those in a simple landscape. In the complex landscape the habitat fragmentation index was 1.54 times greater than in the simple landscape. Habitat fragmentation reduces the effectiveness of the foraging behaviour of natural enemies of pests (Landis et al. 2000). It also affects the searching behaviour of the pests and determines to some extent when and the numbers of aphids that colonize the fields. There are many predators and parasitoids of aphids in wheat fields. In the complex landscape the rapid growth of the wheat aphid populations may be because the habitat fragmentation there reduced the efficiency with which the natural enemies were able to find and consume aphids. In the complex landscape studied the population growth rates of the three species of wheat aphids were higher than in the simple landscape.

\section{Conclusion}

In order to determine the effect of landscape structure on the population dynamics of wheat aphids we need to study in greater detail the following aspects: (1) the relationship between the complexity of the landscape and the ability of wheat aphids to locate their host plants and their subsequent population growth rate, (2) the question, whether the greater habitat fragmentation of complex landscapes adversely affects the foraging for aphids of predators and parasitoids and (3) which structures of complex landscapes affect the foraging for aphids by predators and parasitoids.

\section{Acknowledgements}

Funding for this project was provided by Henan Province, Science and Technology (Grant\#132102110021 and 122102110171) and the Key Teacher Support Program of Henan University (Grant\#2012GGJS-219).

\section{Disclosure}

J-H L, M-F Y, W-Y C and L S designed and performed the experiments. A A and Z-H Z analyzed the data and wrote the manuscript.

\section{REFERENCES}

Andrén H (1994) Effects of habitat fragmentation on birds and mammals in landscapes with different proportions of suitable habitat. Oikos 71: 355-366.

Baguette M, Schtickzelle N (2003) Local population dynamics are important to the conservation of meta-population in highly fragmented landscapes. J Appl Ecol 40: 404-412.

Bianchi FJJA, Goedhart PW, Baveco JM (2008) Enhanced pest control in cabbage crops near forest in The Netherlands. Landscape Ecol 23: 595-602.

Boutin S, Hebert D (2002) Landscape ecology and forest management, developing an effective partnership. Ecol Appl 12:390-397.

Costamagna AC, Menalled FD, Landis DA (2004) Host density influences parasitism of the armyworm Pseudaletia in agricultural landscapes. Basic Appl Ecol 5: 347-355.

Dauber J, Hirsch M, Simmering D, Waldhardt R, Otte A, Wolters V (2003) Landscape structure as an indicator of biodiversity, matrix effects on species richness. Agr Ecosyst Environ 98: 321-329.

Debach P, Rosen D (1991) Biological Control by Natural Enemies. Cambridge University Press, Cambridge.

Haila Y (2002) A conceptual genealogy of fragmentation research, From island biogeography to landscape ecology. Ecol Appl 12: 321-334.

Hassan DA, Parisey N, Burel F, Plantegenest M, Kindlmann P, Butet A (2012) Relationship between landscape composition and the abundance of aphids and their natural enemies in crop fields. Eur J Environ Sci 2: 89-101.

Landis DA, Wratten SD, Gurr GM (2000) Habitat management to conserve natural enemies of arthropod pests in agriculture. Annu Rev Entomol 45: 175-201.

Naylor RL, Ehrlich PR (1997) Natural pest control services and agriculture. In: Daily GC (ed.) Nature's services, societal dependence on natural ecosystems. Washington, DC, Island Press, pp. 151-174.

Roland J, Taylor PD (1997) Insect parasitoid species respond to forest structure at different spatial scales. Nature 386: 710-713.

Tscharntke T, Brandl R (2004) Plant-insect interactions in fragmented landscapes. Ann Rev Entomol 49: 405-430.

Vollhardt MG, Tscharntke T, Wackers FC, Bianchi FJJA, Thies C (2008) Diversity of cereal aphid parasitoids in simple and complex landscapes. Agr Ecosyst Environ 126: 289-292.

Wagner HH, Peter JE (2001) Quantifying habitat specificity to assess the contribution of a patch to species richness at a landscape scale. Landscape Ecol 16: 121-131.

Wu JG, Richard H (2002) Key issues and research priorities in landscape ecology, an idiosyncratic synthesis. Landscape Ecol 17: 355-365

Zhao ZH, Guan XQ, He DH (2012). Community composition of parasitoids and hyperparasitoids of wheat aphids in different agricultural landscapes. Chinese J Appl Entomol 59: 220-228.

Zhao ZH, Shi Y, He DH (2010). Population dynamics of wheat aphids in different agricultural landscapes. Acta Ecol Sinica 30: 6380-6388. 